\title{
THE INTERACTION OF CHLORIN PHOTOSENSITIZERS WITH POTENTIAL NANOSCALE CARRIES
}

A.V. Kustov ${ }^{1,2}$, P.K. Morshnev',2, O.V. Shykhto², T.V. Kustova², V.P. Zorin ${ }^{3}$, T.E. Zorina ${ }^{3}$, D.B. Berezin ${ }^{2}$

${ }^{1}$ United Physical Chemical Center of Solutions, G.A. Krestov Institute of Solution Chemistry, Russian Academy of Sciences, 153045 Russia, Ivanovo, Academiskaya str., 1.

${ }^{2}$ Department of Organic Chemistry, Ivanovo State University of Chemistry and Technology, 153012 Russia, Ivanovo, Sheremetev av, 7.

${ }^{3}$ Department of Biophysics, Belarussian State University, Belarus, Minsk, Nezavisimosti av, 7

DOI: 10.19163/MedChemRussia2021-2021-28

E-mail: kustov@isuct.ru

Photodynamic therapy (PDT) uses appropriate photosensitizers (PSs) that are activated by red light to form reactive oxygen species viz. singlet oxygen ${ }^{1} \mathrm{O}_{2}$ (Type II photochemical mechanism) or various radical forms $\left(\mathrm{HO} \bullet, \mathrm{O}_{2} \bullet-\right)$ and $\mathrm{H}_{2} \mathrm{O}_{2}$ (Type I photochemical mechanism). These species oxidize biomolecules and destroy malignant or microbial cells inducing necrosis or apoptosis [1, 2]. Antimicrobial photodynamic therapy (APDT) can treat localized bacterial or fungal infections, whereas antitumor PDT focuses on treating superficial tumors [2]. In this short communication, we consider the results of our recent studies on the interaction of cationic or anionic chlorin photosensitizers (PSs) of second generation with potential nanoscale carries such as non-ionic surfactant Tween 80 (a) and some polymers viz. polyvinylpyrrolidone (b), $\varepsilon$-polylizine (c), pluronic P123 (d) by the absorption and fluorescence spectroscopy techniques.

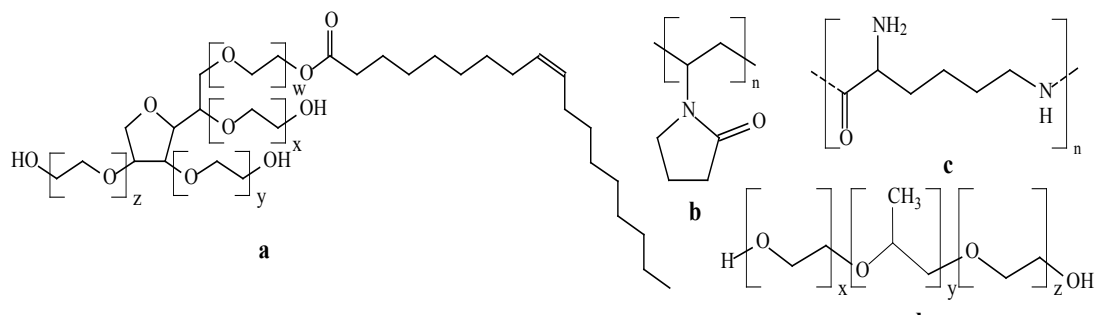

d

Our results indicate that both cationic and anionic macrocycles form stable complexes with potential carrier systems, the PS molecules being located in the periphery of micelles nearby the hydrophilic head groups of the carrier molecules. Other details of this investigation viz. the PS structures, their ability to generate singlet oxygen, to associate and aggregate at therapeutic concentrations etc. will be given in the presentation.

The study was supported by Russian Foundation of Basic Researches (Projects 20-03-00153, 20-53-00038)

\section{References}

[1] A.V. Kustov, T.V. Kustova, D.V. Belykh, I.S. Khudyaeva, D.B. Berezin, Dyes Pigm., 2020, 173, 107948.

[2] A.V. Kustov, D.B. Berezin, A.I. Strelnikov, N.P. Lapochkina. Antitumor and antimicrobial photodynamic therapy: mechanisms, targets, clinical laboratory research. A practical guide. A.K. Gagua ed., Moscow, Largo, 2020, 108 p. (in Russian). 